\title{
IDENTIFIKASI NASKAH DOKUMEN TEKS DENGAN METODE INDEXING
}

\author{
Heriyanto \\ Prodi Teknik Informatika UPN "Veteran" Yogyakarta \\ Jl. Babarsari 2 Tambakbayan 55281 Telp (0274) 485323 \\ email : $\mathrm{mr}$ heriyanto skom@yahoo.com
}

\begin{abstract}
In everyday life of text data or copy met by many in old stuff and white colars in our life is everyday. Multimedia which consist of text data aggregate, picture and also voice or present image used by many either through computer, internet, even handphone media. Method make an index to text a copy which is through scanning process and parsing can be used to make index a document copy like within reason thick book usually is in it figured in to index for the seeking of a word in book swiftly and index for line, paragraph and word frequency.

\section{Keywords : indexing, text, line, parsing, scanning, document}

Dalam kehidupan sehari-hari data teks atau naskah banyak dijumpai di perkantoran dan tidak asing lagi dalam kehidupan kita sehari-hari. Multimedia yang terdiri dari kumpulan data teks, suara maupun gambar atau citra yang sekarang ini banyak digunakan baik melalui komputer, internet, bahkan media handphone. Metode indeks teks suatu naskah yang dilakukan melalui proses scanning dan parsing dapat digunakan untuk membuat indeks suatu naskah dokumen seperti layaknya buku-buku yang tebal biasanya di dalamnya disertakan indexing untuk pencarian suatu kata dalam buku dengan cepat dan dilakukan indexing untuk baris, paragraph dan frekwensi kata.
\end{abstract}

Kata kunci : indexing, teks, baris, parsing, scanning, dokumen

\section{PENDAHULUAN}

Melalui pengolah data naskah atau teks maka bagaimana suatu naskah yang ada di dalam buku atau majalah atau sarana di dalam naskah komputer dapat dibuatkan suatu indexing yang dapat memudahkan pencarian data.

a. Bagaimana melakukan dengan proses scanning yang menguraikan satu huruf demi huruf melalui proses pembacaan satu persatu huruf demi huruf.

b. Bagaimana mendeteksi suatu alphabet yang tidak dipakai seperti spasi, koma titik dan lain-lain yang dianggap dibuang.

c. Bagaimana mendeteksi keberadaan suatu paragraph, baris pada suatu naskah

d. Medneteksi berapa banyak kata yang muncul pada suatu paragraph, pada suatu kalimat dan seterusnya.

e. Metode parsing dan scanning untuk menguraikan data huruf dan kata.

f. Menghitung jumlah data kata atau paragraph atau baris pada suatu paragraph.

Pada pembahasan saat ini penulis hanya membatasi pada pengolah data teks melalui proses indek dan pencarian data suatu kata terdapat pada indek dan ditemukan identifikasi kata tersebut ada di berbagai paragraph maupun baris dan frekwensi kemunculannya.

\section{TINJAUAN PUSTAKA}

Spark Jones 1997 (dalam Rhodes, 2000; hal 45) menyatakan bahwa pencarian dokumen dikelompokkan pada dua aktivitas yang saling berkaitan satu dengan lainnya yaitu : indeks dan pencarian. Indeks mengacu pada dokumen itu sendiri, yaitu informasi yang akan dipanggil, dan pencarian yaitu pernyataan dari pemakai yang membutuhkan informasi dengan tujuan untuk menampilkan informasi yang diinginkan.

Lu (1999;75-76) melihat bahwa tujuan dari suatu sistem IR adalah untuk mendapat kembali materi relevan dari suatu database dokumen sebagai jawaban atas query pemakai. 
Kebanyakan dari sistem IR yang komersil saat sekarang dapat digolongkan pada sistem IR boolean atau sistem pencarian text-pattern. Query pencarian text-pattern adalah string atau ungkapan reguler.

Di dalam suatu file inverted untuk masing-masing istilah merupakan suatu indeks terpisah yang dibangun itu menyimpan record pengenal untuk semua arsip yang berisi term. Suatu masukan file inverted pada umumnya berisi suatu kata kunci dan sejumlah dokumen Identitas. Masing-masing kata kunci atau istilah dan document-Ids dari dokumen yang berisi kata kunci diorganisasi ke dalam satu baris. Suatu contoh dari suatu file inverted ditunjukkan dibawah ini :

Term 1: Record1, Record3

Term 2 : Record 1, Record 2

Term 3 : Record 2, Record 3, Record 4

Term 4 : Record 1, Record 2, Record 3, Record 4

Dimana term I (I menjadi 1,2,3 atau 4) adalah nomor ID jumlah indek masukan I, record I (menjadi 1,2,3 atau 4) adalah nomor ID jumlah record I atau dokumen I (Lu,1999;hal 77).

Teknik yang dipakai untuk dokumen teks banyak digunakan dengan teknik IR (Indexing dan Retrieval). Teknik IR sangatlah penting di dalam informasi multimedia manajemen sistem untuk dua alasan yaitu :

1. Keberadaannya, sebagian besar dokumen teks banyak digunakan di dalam organisasi seperti perpustakaan.

Teks adalah sangat penting sumber informasi untuk organisasi. Untuk pengefisienan penggunaan penyimpanan informasi dalam naskah sangat diperlukan sistem IR.

2. Teks dapat digunakan untuk kebutuhan media lain seperti Audio, Gambar dan Video. (menurut Buku Multimedia Database Management System, Guojun Lu Hal 73)

Ada 4 penggunaan komponen model IR (Indexing Retrieval) yaitu :

1. Exact Match

2. Vector Space

3. Probabilistic

4. Cluster-based

(menurut Buku Multimedia Database Management System, Guojun Lu Hal 73)

Namun sebagian besar menggunakan teknik exact Match dalam model boolean.

Text Documents di proses seperti dilakukan indeks yang tersimpan dalam database yang merupakan document representation lalu query /permintaan yang diinputkan oleh user atau dilakukan entry data query maka diproses dan merupakan query representation kemudian dicocokan apa yang ada pada query dengan apa yang ada pada databases diserver dilakukan comparison (similary calculation) maka merupakan hasil retrieved documents apakah data hasil retrieved documents tersebut sudah relevance seperti yang diinginkan atau yang dicari jika tidak maka feed back dilakukan permintaan /query lagi oleh user kembali ke awal query atau query representation yang sudah ada tadi dicari lagi. Contoh misalkan dalam search engine pada saat user melakukan query pada query representation dilakukan pencarian kata haji maka dilakukan pencocokan dengan text document yang ada pada proses di indeks database berupa document representation lalu dilakukan pencocokan similary calculation dan ditampilkan hasilnya beberapa nama yang mendekati kata haji diretrieved documents apabila tidak sesuai dengan yang dicari atau tidak relevance maka kembali lagi ke query atau ke query representation yang sudah ada tersebut.

Adapun tujuan yang ingin dicapai penulis antara lain :

1. dapat membuat indek pada suatu naskah atau dokumen teks surat

2. dapat melakukan pencarian kata terdapat pada naskah dengan menamplilkan paragraph, baris, dan frekwensi kemunculan data.

Manfaat

Adapun beberapa manfaat yang didapat yaitu :

mengetahui kata tertentu dengan tepat dan cepat berdasarkan indeks yang sudah dic create menemukan posisi data dimanapun berada baik paragraph, baris, dan frekwensi kemunculannya.

\section{METODE PENELITIAN}

Metode penelitan dengan metode indexing. Dokumen teks atau naskah dapat melakukan indek dengan menganalisa sebagai berikut :

a. Data teks terdiri dari beberapa paragraph 
b. Data paragraph terdiri atas beberapa baris

c. Data kata terdiri atas kemunculan / jumlah kemunculan atau frekwensi.

Tahap Pertama

Makanan bakso munir bangga yang mudah ditemukan dimana-mana, di Indonesia merupakan budaya munir bangga mengandung adi luhur bangsa. Dimana budaya Indonesia sangat rukli nilainilai luhur budaya rizki bakso rizki yang bangga bakso pemuda rukli bangsa Indonesia yang luhur budi pekerti dan akhlaknya rukli heri, rizki.

Proses pembacaan data dengan scanning teks atau naskah teks misalkana apabila dilakukan indek maka :

\{mengambil dokumen data.txt ke richedit\}

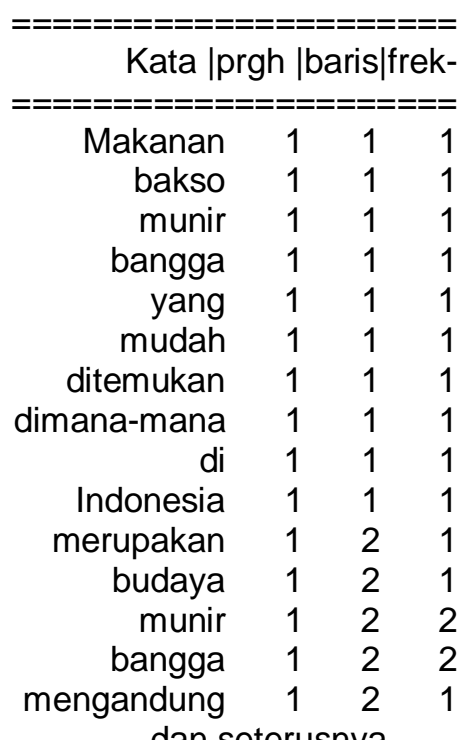

procedure TForm1.BitBtnBacaClick(Sender: TObject);

var baris:string;

begin

RichEdit1.Clear;

Assignfile(berkastext,'data.txt');

reset(berkastext);

while not (eof(berkastext)) do

begin

readln(berkastext,baris);

RichEdit1.Lines.Add(baris);

end;

closefile(berkastext);

\{tutup file\}

end;

TAHAPAN INDEKS

CARI KATA

Proses indek

Gambar 1. Indek yang dicari 


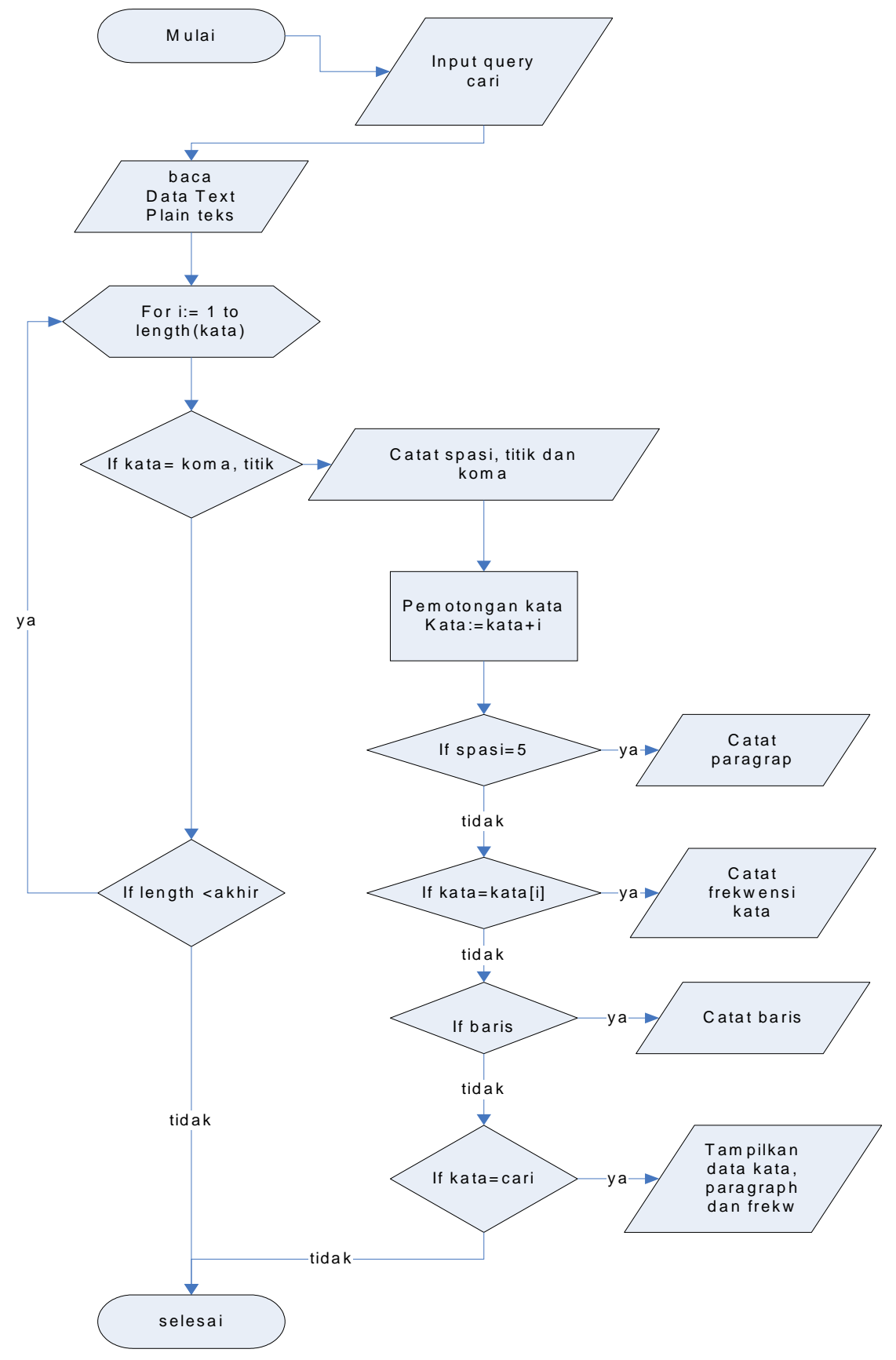

Gambar 2. Flow Chart pembacaaan kata

Algoritma pembacaan perkata

0 . Mulai

1. Masukkan query

2. Baca teks

3. For I 1 to length kata

4. Jika If kata=spasi koma titik

5. Catatat koma titik spasi

6. Spasi maka Kata=kata+kata[l] 
7. Jika spasi-5 maka paragrh

8. Jika kata=kata[l] maka catat frek

9. Jika akhir baris maka cata baris

10. Cek jika cari=kata maka tampilkan

11. Jika length < akhir maka lanjut 3

12. Jika tidak langkah 13

13. selesai

Algoritma pencarian kata

1. Mulai Baca Data

2. Scanning

3. Tokken=token spasi titik dan koma di hilangkan

4. Tahapan parshing pada kata-kata dengan mendeteksi dengan representasi diantaranya:

Paragraph dengan spasi 5 maka paragraph

Jika ketemu spasi, titik dan koma maka itu kata

Kata sampai dengan length kalimat maka satu baris

Catat frekwensi kata yang sama kata=kata[l];

5. Tampilkan hasil

Catat paragprah dan baris dengan counter

Bagan Proses Indexing

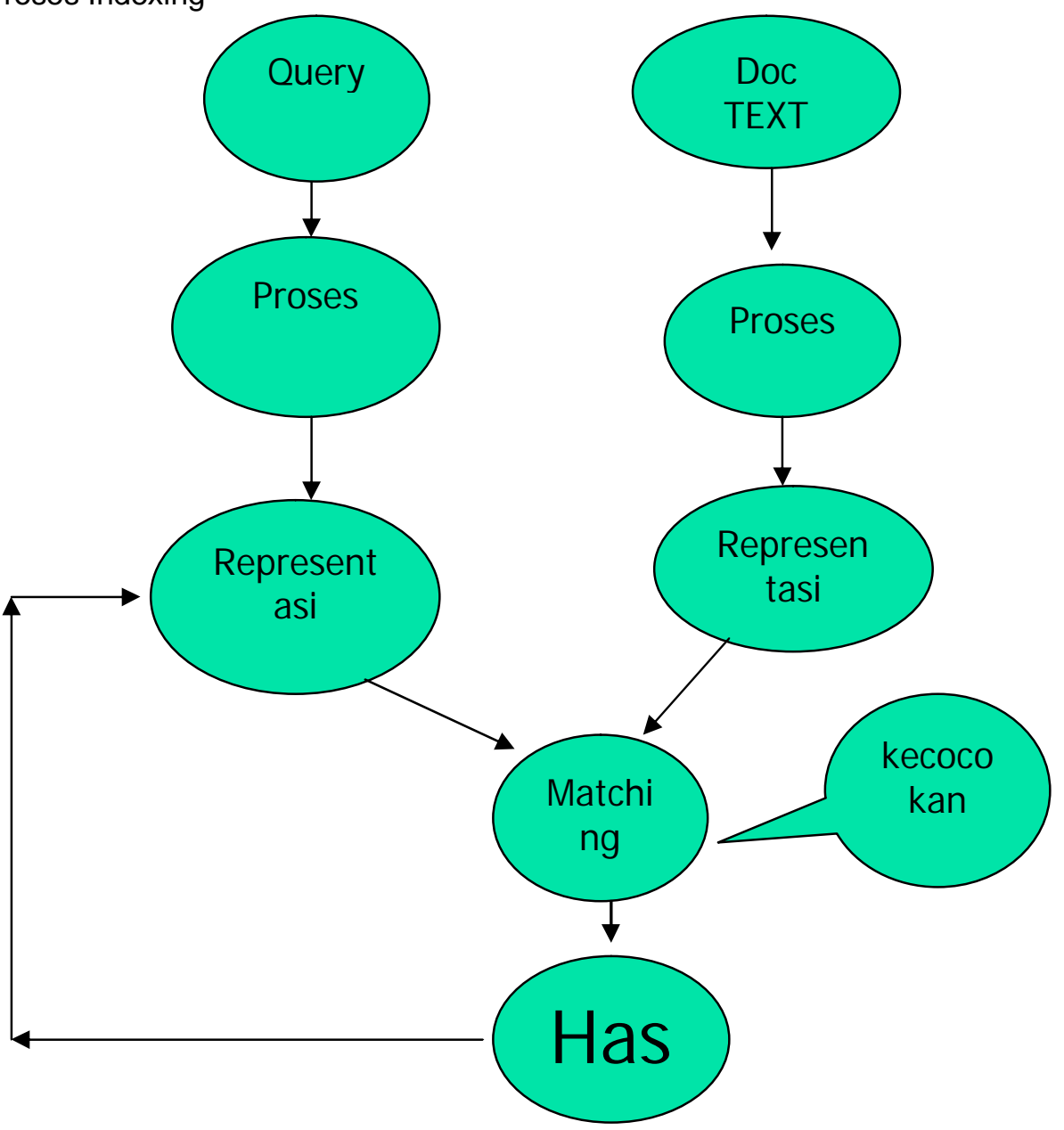

Gambar 3. Proses Indexing

Data query yang diminta akan dicek dengan dokumen teks dilakukan proses indek dengan representasi antara data proses indeks dengan dengan dokumen dilakukan kecocokan dengan 
matching dilakukan counter baik paragraph, baris dan jumlah kata dalam frekwensi kemunculan.

\section{DESAIN DAN RANCANGAN}

Dalam program tampilan rancangan sebagai berikut :

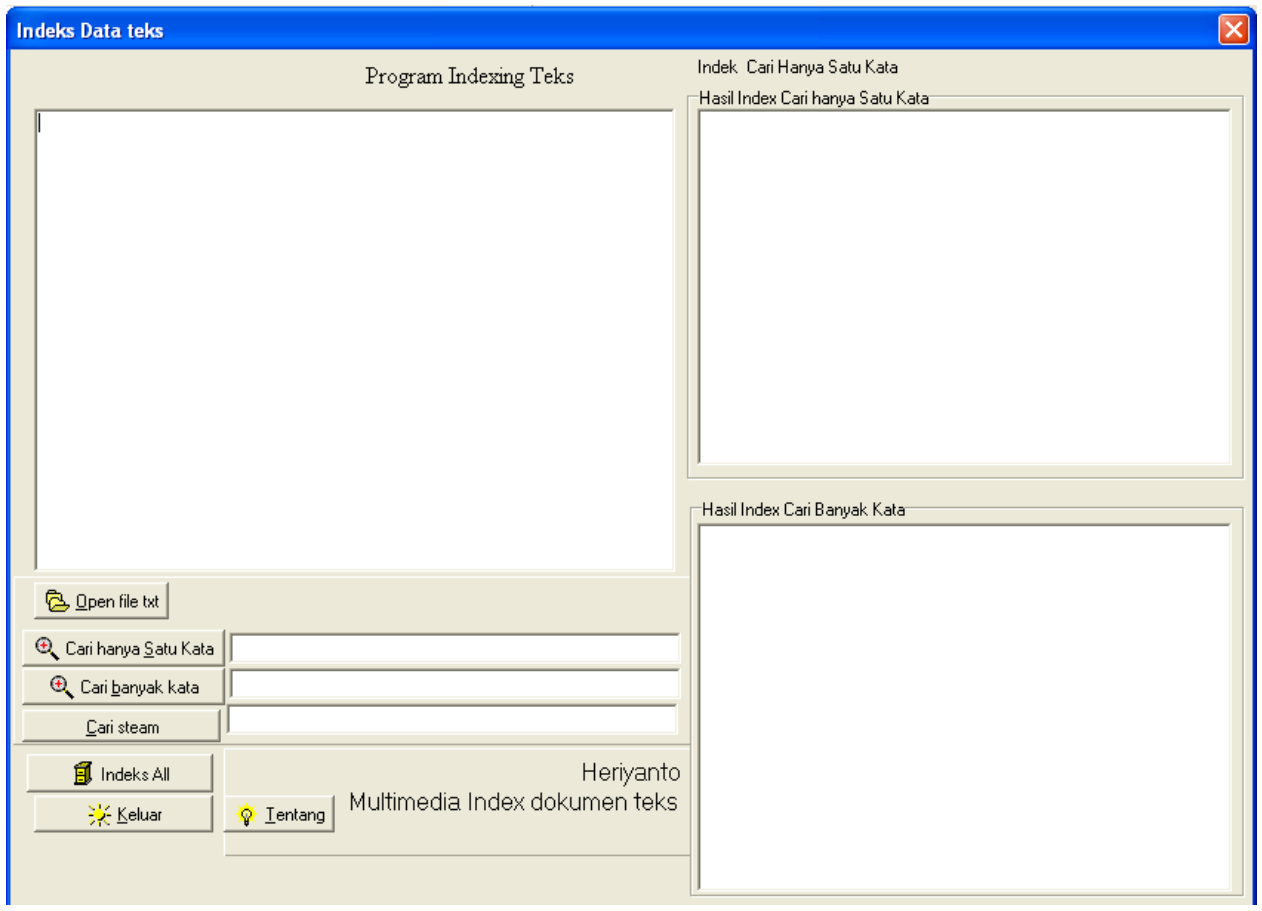

Gambar 4. menu utama indexing

Tampilan menu utama indexing menu sebelah kiri data sumber naskah dokumen teks dapat diambil dari file atau open folder.

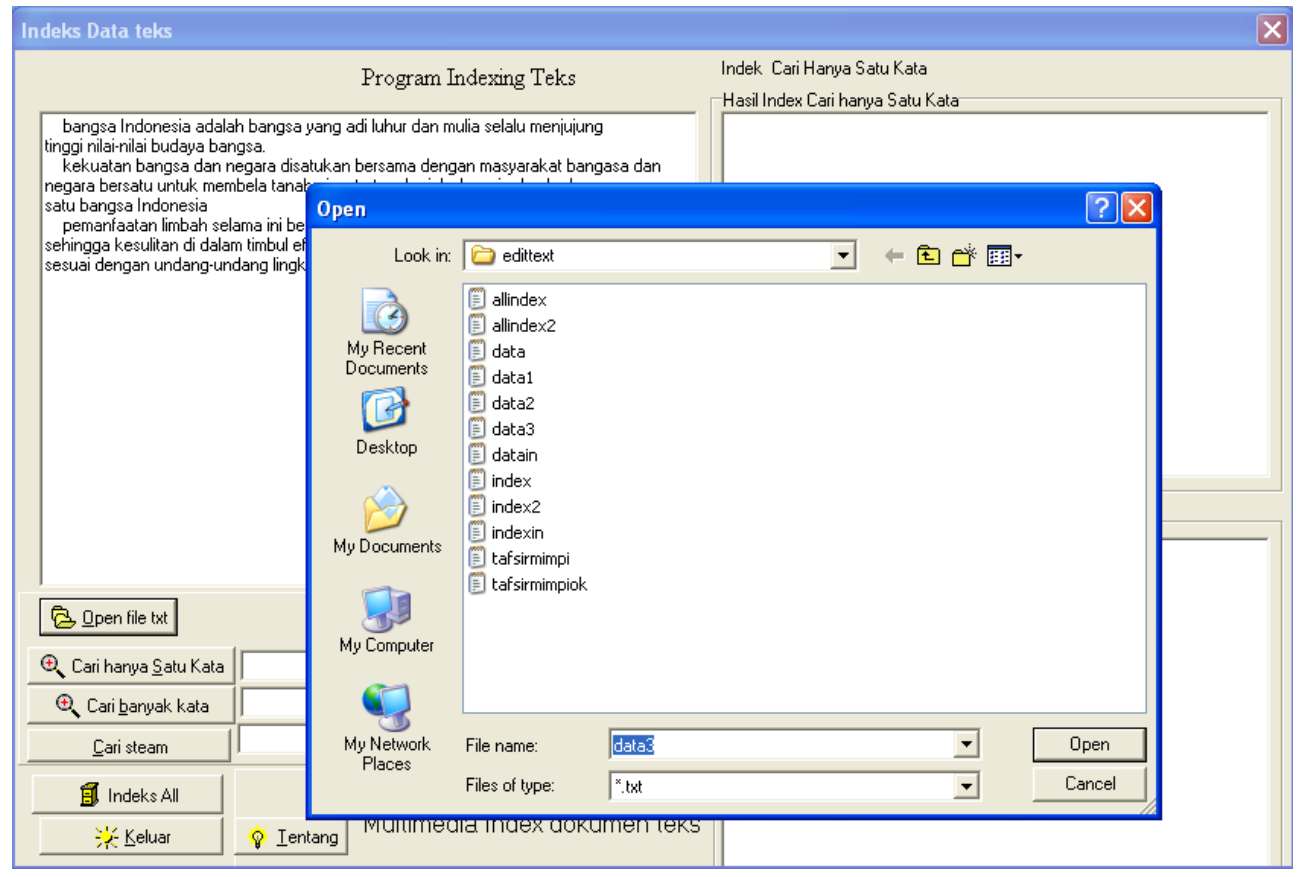

Gambar 5. membuka dokumen teks pada data file 
Program Indexing Teks

bangsa Indonesia adalah bangsa yang adi luhur dan mulia selalu meniujung kekuatan bangsa dan negara disatukan bersama dengan masyarakat bangasa dan negara bersatu untuk membela tanah air satu tanah air Indonesia dan berbangsa, satu bangsa Indonesia

pemanfaatan limbah selama ini belum semaksimal mungkin untuk di daur ulang sehingga kesulitan di dalam timbul erek negatif berupa pencemaran di mana-mana

Open file txt

\begin{tabular}{|c|c|c|}
\hline \multicolumn{3}{|l|}{ @ Cari hanya Satu Kata } \\
\hline @ Cari banyak kata & untuk dan tan & \\
\hline Cari steam & & \\
\hline 自 Indeks All & & Heriyanto \\
\hline 洨 Keluar & $\mathbb{Q}$ Ientang & Thutintre \\
\hline
\end{tabular}

Indek Cari Hanya Satu Kata

Hasil Index Cari hanya Satu Kata File Sumber: Data.txt. ......... File Hasil : Index.tyt

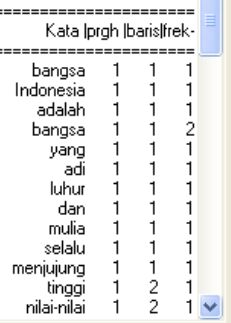

nilai-nilai

Hasil Index Cari Banyak Kał

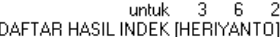
File Sumber: Data.txt …...... File Hasil : Index.tst

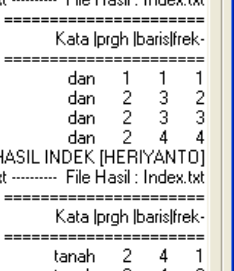

Gambar 6. melakuan indek data kata untuk dan tanah

Program indexing data diambil dari file dilakukan pencarian kata dengan banyak kata ditampilkan di sebelah kanan.

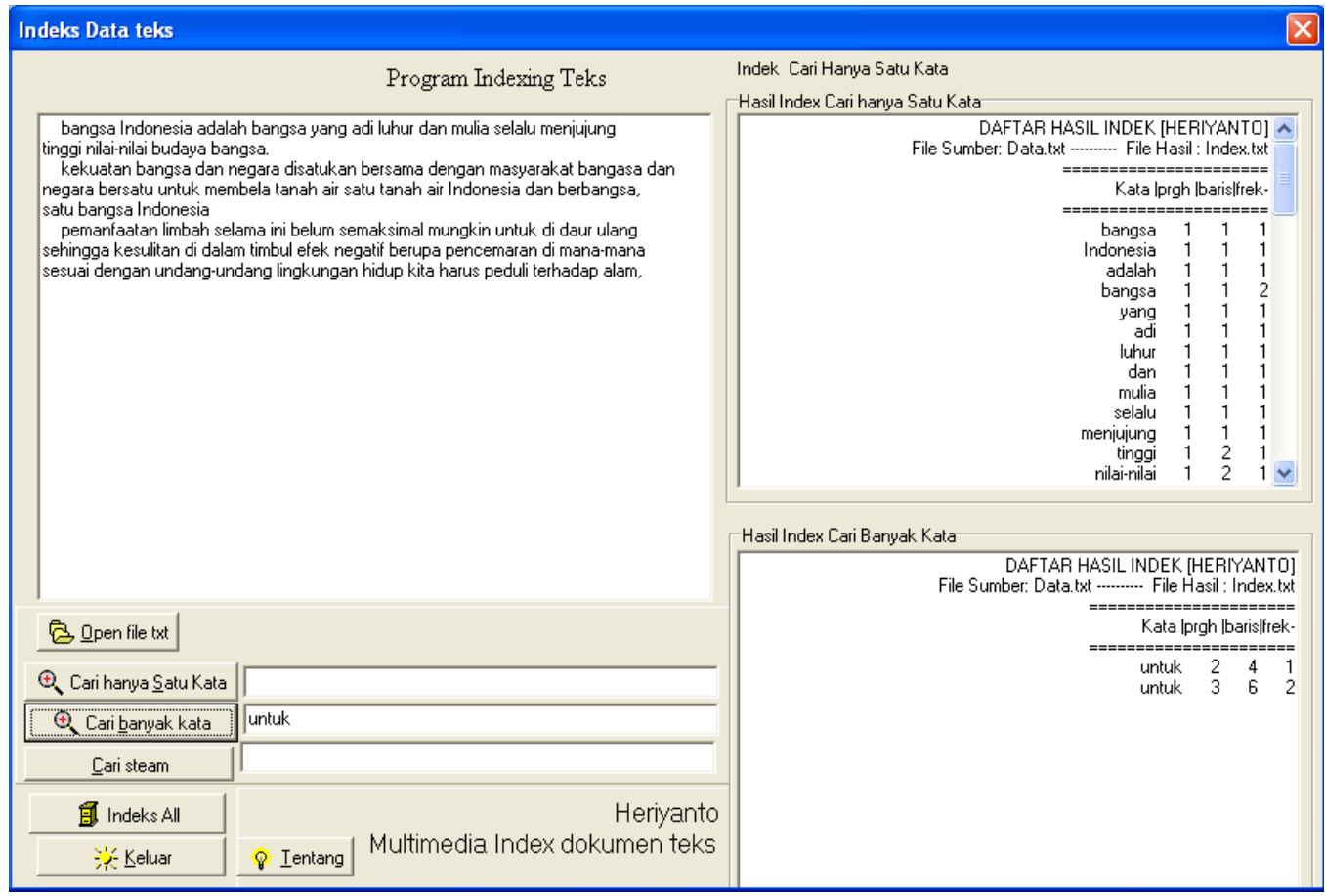

Gambar 7. melakuan pencarian data kata "untuk 


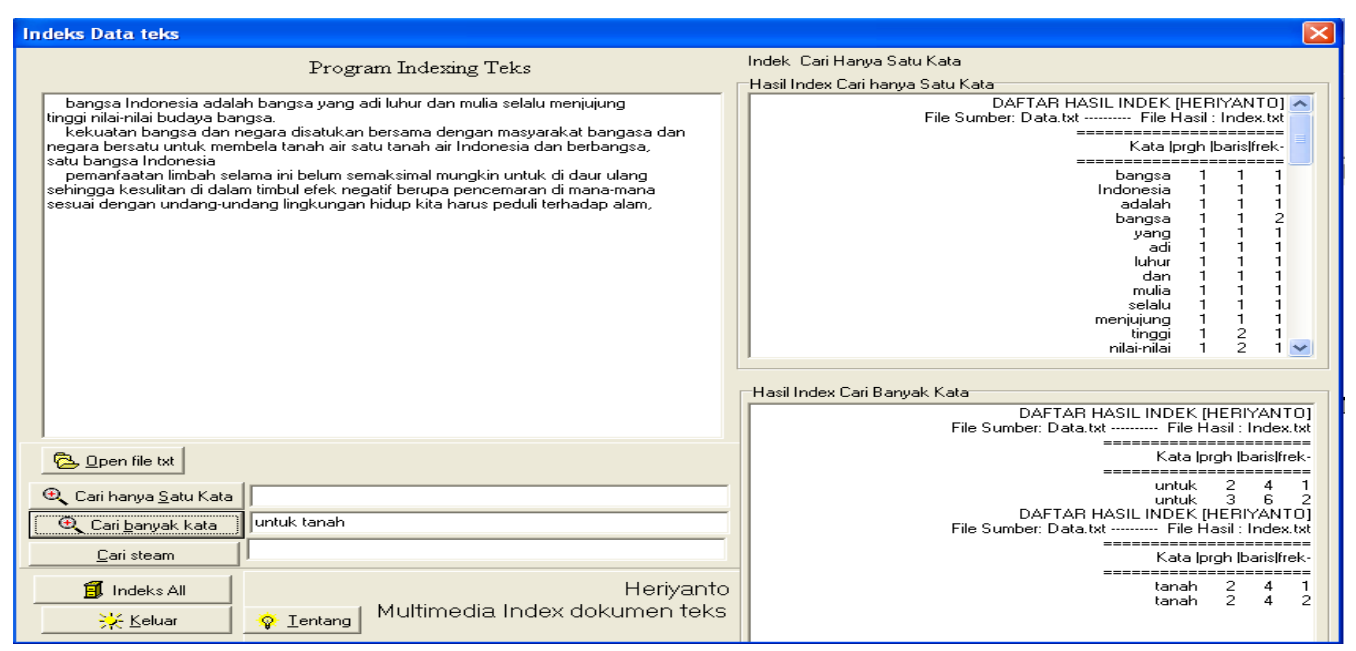

Gambar 8. melakuan pencarian data kata "untuk" dan "tanah"

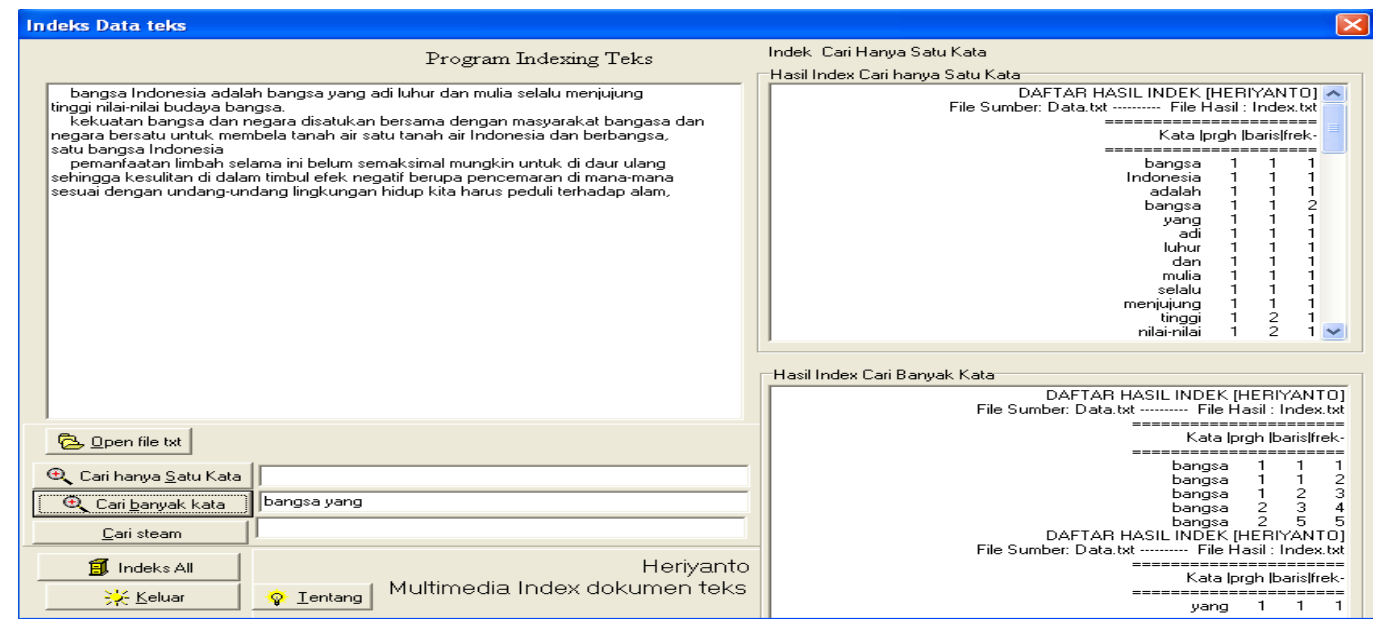

Gambar 9. melakuan pencarian data kata

Hasil pencarian banyak kata ditampilan letak paragraph, letak pada baris dan jumlah kata.

\section{KESIMPULAN}

Secara garis besar sistem yang dibangun untuk mengetahui naskah sumber dan naskah target dilakukan untuk identifikasi dengan pembuatan indeks mencari letak kata, paragraph dan jumlah frekwensi kata tersebut dalam suatu paragraph. Melakukan scanning awal pertama untuk memisahkan kata, koma, titik dan dilakukan identifikasi pasda masingmasing kata terdapat pada baris, paragraph dan frekwensi kata tersebut. Pencarian selanjutnya dengan mengecek keberadaan kata tersebut dengan pencarian satu kata, dua kata atau banyak kata maka dilakukan indeks data kata tersebut terdapat pada baris, paragraph dan kemunculan kata tersebut dengan menghitung counter frekwensi kata tersebut.

\section{DAFTAR PUSTAKA}

Candra, Ian , Utility Komputer Multimedia, 1999, Elex Media Komputindo, Jakarta Lu, Guajun, Multimedia Database Manajemen Systems, 1999 Artech House, Inc Martina, Inge, 36 Jam Belajar Komputer Delphi 5.0 Database Client/Server Menggunakan Delphi, 2000, PT. Elex Media Komputindo, Jakarta

Sanjaya Dwi, Bertualang dengan Struktur Data di Planet Pascal, edisi Pertama 2001, J\& J Learning Yogyakarta

Silberschatz, Korth, Sudarsan, Databases Systems Concept, $4^{\text {th }}$ ed, 2002, McGrawHill 